\title{
Glass lonomer Restorative Materials Response to Its Color Stability with Effect of Energy Beverages
}

\author{
Khalid H Al-Samadani
}

\begin{abstract}
Introduction: To evaluate the effects of energy drinks on glass ionomers $(\mathrm{Gl})$ restorative materials color stability after different periods of aging time.
\end{abstract}

Materials and methods: Glass ionomers disks, $8 \mathrm{~mm}$ diameter, $3 \mathrm{~mm}$ thickness within Teflon beverages are Code Red, Red Bull, and Power Horse. Specimens were tested for aging in beverages (Code Red, Red Bull, and Power Horse). The distilled water was used as a control. The variations in color were evaluated in the CIELAB [CIE L*a*b* (CIELAB) is a color space specified by Commission International de Eclairage (CIE)] using a colorimeter pre- and post-storage period. Color differences $\left(\Delta \mathrm{E}^{*}{ }_{\mathrm{ab}}\right.$, $\left.\Delta b^{*}\right)$ in each specimen were recorded. The t-test analysis was performed ( $p<0.05$ was considered as significant).

Results: The color changes by Code Red, Red Bull, and Power Horse energy drinks were significantly different for all tested materials $(p<0.05)$. Each specimen exhibited total color changes toward yellowness, after a period of 1,7 , and 30 days. The greatest color difference $\left(\Delta \mathrm{E}^{*}{ }_{\mathrm{ab}}\right)$ was observed in the case of Red Bull group following 1 week.

Conclusion: The energy beverages affected the color stability of tested GI restorative materials with the increase of aging time. The effect on the color stability of GI was influenced by factors, such as the type of solution and the presence of the acids causing erosion.

Clinical significance: Glass ionomer is used as cosmetic filling material. Energy beverages have erosive effect on glass ionomer which influences clinical importance by influencing on mastication and TMJ problem.

Keywords: Aging, Colorimeter, Energy drinks, Glass ionomers cement, Red bull.

How to cite this article: Al-Samadani $\mathrm{KH}$. Glass lonomer Restorative Materials Response to Its Color Stability with Effect of Energy Beverages. World J Dent 2017;8(4):255-261.

\section{Source of support: Nil}

Conflict of interest: None

\section{INTRODUCTION}

Glass ionomer (GI) restorative materials have many unique properties, such as adhesion to tooth structure, biological compatibility, and anticariogenic properties due to release

Department of Restorative Dental Science, College of Dentistry Taibah University, Al Madinah Al Munawwarah, Kingdom of Saudi Arabia

Corresponding Author: Khalid H Al-Samadani, Department of Restorative Dental Science, College of Dentistry, Taibah University, Al Madinah Al Munawwarah, Kingdom of Saudi Arabia, e-mail: kalsamadani@gmail.com of fluoride from the materials. ${ }^{1}$ The ability to withstand masticatory stresses and a variety of media in the mouth of restorative materials as well as stability of color is vital for their clinical performance for a reasonable period of time. ${ }^{2,3}$ Energy drinks in different brands are marketed all over the world and the youngster are very much used to these drinks. America is one of the largest consumers of energy beverages and, roughly, American consumed 290 million gallons beverage in 2007., ${ }^{4,5}$ Color stability of materials is considered as one of the most important factors when selecting GI restorative materials for restoration. ${ }^{6,7}$ The previous studies have shown that the effect of intrinsic discoloration was very small in restored GI filling materials..$^{8-10}$ No dental materials nowadays have ideal properties for any dental application. Therefore, GI restorative materials also have a number of drawbacks, such as brittleness, prone to fracture poor wear resistance, and inadequate surface properties. ${ }^{11,12}$

Currently available instruments are known for quantitative assessment of the acrylic resin color changes reliably. ${ }^{13}$ They record the color variation and express in the form of three coordinate values $\left(\mathrm{L}^{*}, \mathrm{a}^{*}\right.$, and $\left.\mathrm{b}^{*}\right)$ locating the object's color within CIELAB color space. The $L^{*}$ coordinate represents the brightness, $\mathrm{a}^{*}$ represents the chroma of green or red, and $b^{*}$ represents the chroma of yellow or blue. The color difference $(\Delta \mathrm{E})$ of two objects is determined by the differences of respective coordinates. The formula used to calculate the color differences is as follows: $:^{13,14}$

$$
\Delta \mathrm{E}^{*}{ }_{\mathrm{ab}}=\left[\left(\Delta \mathrm{L}^{*}\right)^{2}+\left(\Delta \mathrm{a}^{*}\right)^{2}+\left(\Delta \mathrm{b}^{*}\right)^{2}\right]^{1 / 2}
$$

Where $L^{*}, a^{*}$, and $b^{*}$ are variations in color parameters for the two specimens. Numeric description of color allows accurate definition of the magnitude of the color variations.

Various thresholds for color differences in dental materials have been reported. ${ }^{14}$ Under the uncontrolled clinical conditions, such small differences in color would be unperceivable as average color differences below 3.7 are rated a "match" in clinical conditions. ${ }^{15}$ Therefore, the aim of this study is to assess the color stability of GI material with the effect of three energy drinks after different periods of aging time.

\section{MATERIALS AND METHODS}

Three types of energy beverages, Code Red, Red Bull, Power Horse, and distilled water as a control were evaluated. 
Their effects on the color stability of three different GI: Ionofil Plus AC self-adhesive restorative system (VocoGermany), GC EQUIA self-adhesive posterior restorative system EQUIA (GC-Japan), and Ketac molar self-adhesive restorative system (3M ESPE-Germany) were immersed in the three groups of energy beverages for 1 day, 1 week, and 1 month and stored at $37^{\circ} \mathrm{C}$. The three energy beverages and the GI used in this study were tabulated in Table 1 . The total of 60 specimens of the GI restorative materials were prepared, as five specimens for each tested material in each group of different immersion groups (energy beverages).

\section{Specimen Preparation}

The preparation of the specimens for the tested GI was dispended and manipulated according to the manufacturer's instructions. The molds fabricated with the Teflon types, measuring $8 \mathrm{~mm}$ internal diameter and $3 \mathrm{~mm}$ height, which was used to fabricate the specimens. The injecting gun method was used to completely fill the molds with all types of tested materials for each group. Using a glass microscope slide, overlaid with a cover glass (BDH borosilicate glass) to act as a separator, was placed at each open end of the Teflon mold. The dual function of it was to compact of the material into a flat surface and to act as a separator between the glass microscope slide and the mold. The specimens were stored at room temperature at ambient conditions till all tested specimens prepared.

Table 1: Glass ionomers and energy beverages used

\begin{tabular}{|c|c|c|c|}
\hline Material & Type & Shade & Manufacturer \\
\hline $\begin{array}{l}\text { lonofil Plus } \\
\text { AC }\end{array}$ & Glass ionomers & $\mathrm{A}_{2}$ & $\begin{array}{l}\text { Voco- } \\
\text { Germany }\end{array}$ \\
\hline GC EQUIA & $\begin{array}{l}\text { Self-adhesive posterior } \\
\text { restorative system EQUIA }\end{array}$ & $\mathrm{A}_{2}$ & GC-Japan \\
\hline $\begin{array}{l}\text { Ketac } \\
\text { molar }\end{array}$ & Glass ionomers & $\mathrm{A}_{2}$ & $\begin{array}{l}\text { 3M ESPE - } \\
\text { Germany }\end{array}$ \\
\hline Code Red & $\begin{array}{l}\text { Carbonated water, sugar, } \\
\text { citric acids, trisodium } \\
\text { citrate E331, taurine, } \\
\text { caffeine, preservative } \\
\text { sodium benzoate } \\
\text { E211, inositol, vitamins, } \\
\text { niacin, pantothenic acid, } \\
\text { vitamins, and approved } \\
\text { colors }\end{array}$ & - & $\begin{array}{l}\text { Made in } \\
\text { Kingdom of } \\
\text { Saudi Arabia }\end{array}$ \\
\hline Red Bull & $\begin{array}{l}\text { Sucrose, glucose, acidity } \\
\text { regulatory sodium, } \\
\text { caffeine, vitamins, natural } \\
\text { flavors, and colors }\end{array}$ & - & $\begin{array}{l}\text { Red Bull } \\
\text { GmbH, } \\
\text { Austria }\end{array}$ \\
\hline $\begin{array}{l}\text { Power } \\
\text { Horse }\end{array}$ & $\begin{array}{l}\text { Carbonated water, } \\
\text { sucrose, glucose, citric } \\
\text { acid, taurine, caffeine, } \\
\text { color, inositol, niacin, } \\
\text { pantothenic acid, and } \\
\text { vitamins }\end{array}$ & - & $\begin{array}{l}\text { S. Spitz } \\
\text { GmbH, } \\
\text { Attnang- } \\
\text { Puchheim, } \\
\text { Austria }\end{array}$ \\
\hline
\end{tabular}

All specimens were polished with $3 \mathrm{~m}$ Sof-Lex disks to obtain surface standardization and clinical finish while in the Teflon disks, and labeled, then stored in a wide mouth bottle filled with distilled water at $37^{\circ} \mathrm{C}$ for 24 hours. This rehydration simulated the 1st day of service for GI restorations in the oral environment. The materials used in this study imbibe water with initial 24 hours of immersion. ${ }^{16-20}$

The total color difference $\Delta \mathrm{E}_{\mathrm{ab}}^{*}$ and $\Delta \mathrm{b}^{*}$ profile (baseline) of all specimens, measured before aging with different four groups, were measured before exposure to all energy beverages with a colorimeter (Konica Minolta CR-400/410; Minolta Co., Osaka, Japan); a color measurements of all specimens were performed according to the CIE L*a* $b^{*}$ color scale relative to the standard illuminant D65 over a white background with using Commission International del Eclairage (CIE). L*a*b* relative to standard, illuminate A, against a white background. Since color differences were being tested, the choice of the illuminate was not important. The calibration of the colorimeter was performed following the manufacturer's instructions before testing each material.

\section{Immersion of the Specimens}

About $150 \mathrm{~mL}$ of each type of energy beverages, according to the manufacturer suggestion, were prepared for aging of the tested specimens of GI restorative materials, were done by preparation of a standard amount of energy beverages solution for immersing medium was prepared to all groups, were the group I was Code Red; group II was Red Bull, group III was power horse and group IV was distilled water (control), for 1 day, 1 week, and 1 month at $37^{\circ} \mathrm{C}$.

All prepared specimens for this study were immersed (aged) in the energy beverages solution (energy drinks) in different groups to evaluate the measurement of total color difference $\Delta \mathrm{E}_{\mathrm{ab}}^{*}$ and $\Delta \mathrm{b}^{*}$ of the GI restorative materials at different immersion time intervals. The specimens of the each three GI restorative materials were immersed in the solution of the groups I to IV (control), for 1 day, 1 week, and 1 month at $37^{\circ} \mathrm{C}$. At the end of each immersion period, the specimens were dipped 10 times in cleansing solution, consisting of $10 \mathrm{~mL}$ soap and $900 \mathrm{~mL}$ distilled water and subsequently, flushed with running tap water and then the excess water on the surfaces was removed by gentle drying by tissue paper. All the specimens were re-immersed in fresh solutions following measurement of $\Delta \mathrm{E}_{\mathrm{ab}}^{*}$ and $\Delta \mathrm{b}^{*}$ at each interval time.

Five times measurements of $L^{*}, a^{*}$, and $b^{*}$ values of each specimen after immersion were repeated to each specimen of tested GI restorative materials in all groups with the time elapsed of 1 day, 1 week, and 1 month 
periods. The measurement was done at baseline (before) and at a time intervals of 1 day, 1 week, and 1 month.

Calculation of the mean values of $\Delta \mathrm{L}^{*}, \Delta \mathrm{a}^{*}$, and $\Delta \mathrm{b}^{*}$ after five measurements were automatically calculated by the spectrophotometer and recorded. The color difference $\Delta \mathrm{E}^{*}{ }_{\mathrm{ab}}$ was calculated from the mean $\Delta \mathrm{L}^{*}, \Delta \mathrm{a}^{*}$, and $\Delta b^{*}$ values for each specimen using the following formula. ${ }^{20}$

$$
\Delta E^{*}\left(L^{*} a^{*} b^{*}\right)=\left[\left(\Delta L^{*}\right)^{2}+\left(\Delta a^{*}\right)^{2}+\left(\Delta b^{*}\right)^{2}\right]^{1 / 2}
$$

Where $\Delta \mathrm{L}^{*}, \Delta \mathrm{a}^{*}$, and $\Delta \mathrm{b}^{*}$ are the differences in the $\mathrm{L}^{*}$ $a^{*}$ and $b^{*}$ values respectively, before and after immersion for each time period.

The mean data obtained from the specimens of the materials aged with the test groups at different interval times of 1 day, 1 week, and 1 month were statistically analyzed. The mean values of the different materials in the groups at different aging times were compared. T-test analysis was performed ( $p<0.05$ was considered as significant).

\section{RESULTS}

Total color difference $\Delta \mathrm{E}^{*}{ }_{\mathrm{ab}}$ and $\Delta \mathrm{b}^{*}$ in this study, for each GI restorative materials used in this study, showed its effect on the color stability for the tested materials with aging (immersion) at different time elapsed duration 1 day, 1 week, and 1 month in each different group of energy beverages Code Red, Red Bull, Power Horse, and distilled water (control) was observed its effects in this study.

Total color differences $\Delta \mathrm{E}^{*}$ ab and $\Delta \mathrm{b}^{*}$ for the materials tested were analyzed statistically, using t-test $(\mathrm{p}<0.05)$ level of significance. There were significant differences $(p<0.05)$ in color changes between materials tested at the 1 day, 1 week, and 1 month immersing periods for each group, as seen in Tables 2 to 5. The color stability for the three tested GI materials comparing the pre-immersion (initial values) to the post-immersion (final measurement) $\Delta \mathrm{E}^{*} \mathrm{ab}$, shows that the materials were discolored. In addition, the total color changes exhibited in all groups for the tested materials after time elapsed (1 day, 1 week, and 1 month) were significantly different. The total color difference $\Delta \mathrm{E}_{\mathrm{ab}}^{*}$ shows the discoloration of all materials included in this study clinically impressable.

The total color differences, $\Delta \mathrm{E}^{*}{ }_{\mathrm{ab}}$ increased with increasing time of immersion for the materials in all groups, with some exceptions. For group I, Code Red energy beverages, all the materials' discoloration increased with time elapsed, except that the GC EQUIA and Ketac molar material discoloration did not change increasing at 1 week ( $\mathrm{p}=0.015)$, a highly significant finding. For group II, Red Bull, the $\Delta \mathrm{E}_{\mathrm{ab}}^{*}$ increased with the time interval except for Ketac molar which showed decreased discoloration at 1 week compared to that at 1 day $(p=0.005)$, again a highly significant result. Group III,

Table 2: Total color difference $\Delta \mathrm{E}^{*}{ }_{a b}$ and chroma $\Delta \mathrm{b}^{*}$ for tested $\mathrm{Gl}$ restorative materials immersed in Code Red for different aging periods

\begin{tabular}{lllll}
\hline Materials & $\begin{array}{l}\text { Total color difference } \\
\text { at 1 day }\end{array}$ & $\begin{array}{l}\text { Total color difference } \\
\text { at 1 week }\end{array}$ & $\begin{array}{l}\text { Total color difference } \\
\text { at 1 month }\end{array}$ & $\begin{array}{l}\text { Significant } \\
\text { level }\end{array}$ \\
\hline $\begin{array}{l}\Delta \mathrm{E}^{*}{ }_{\mathrm{ab}} \\
\text { lonofil Plus AC }\end{array}$ & 0.080 & 0.139 & 0.288 & $\mathrm{p}=0.015$ \\
$\mathrm{GC}$ EQUIA & 0.087 & 0.072 & 0.151 & \\
$\quad$ Ketac molar & 0.167 & 0.082 & 0.541 & $\mathrm{p}=0.134$ \\
$\begin{array}{l}\Delta \mathrm{b}^{*} \\
\text { lonofil Plus AC }\end{array}$ & 0.006 & & 0.0473 & \\
GC EQUIA & 0.00975 & 0.0168 & 0.00675 & \\
Ketac molar & 0.0033 & 0.0103 & 0.173 & \\
\hline
\end{tabular}

Table 3: Total color difference $\Delta E^{*}{ }_{\text {ab }}$ and chroma $\Delta b^{\star}$ for tested GI restorative materials immersed in Red Bull for different aging periods

\begin{tabular}{|c|c|c|c|c|}
\hline Materials & $\begin{array}{l}\text { Total color difference } \\
\text { at } 1 \text { day }\end{array}$ & $\begin{array}{l}\text { Total color difference } \\
\text { at } 1 \text { week }\end{array}$ & $\begin{array}{l}\text { Total color difference } \\
\text { at } 1 \text { month }\end{array}$ & $\begin{array}{l}\text { Significant } \\
\text { level }\end{array}$ \\
\hline \multicolumn{5}{|l|}{$\Delta \mathrm{E}^{*}{ }_{\mathrm{ab}}$} \\
\hline Ionofil Plus AC & 0.132 & 0.323 & 0.357 & $p=0.005$ \\
\hline GC EQUIA & 0.100 & 0.984 & 0.550 & \\
\hline Ketac molar & 0.208 & 0.096 & 0.537 & \\
\hline \multicolumn{5}{|l|}{$\Delta b^{*}$} \\
\hline Ionofil Plus AC & 0.0123 & 0.006 & 0.0365 & $p=0.211$ \\
\hline GC EQUIA & 0.00575 & 0.971 & 0.2098 & \\
\hline Ketac molar & 0.034 & 0.0018 & 0.165 & \\
\hline
\end{tabular}


Table 4: Total color difference $\Delta \mathrm{E}^{*}$ ab and chroma $\Delta \mathrm{b}^{*}$ for tested $\mathrm{Gl}$ restorative materials immersed in power horse for different aging periods

\begin{tabular}{lllll}
\hline Materials & $\begin{array}{l}\text { Total color difference } \\
\text { at 1 day }\end{array}$ & $\begin{array}{l}\text { Total color difference } \\
\text { at 1 week }\end{array}$ & $\begin{array}{l}\text { Total color difference } \\
\text { at 1 month }\end{array}$ & $\begin{array}{l}\text { Significant } \\
\text { level }\end{array}$ \\
\hline $\begin{array}{l}\Delta \mathrm{E}^{*}{ }_{\mathrm{ab}} \\
\text { lonofil Plus AC }\end{array}$ & 0.266 & 0.254 & & $\mathrm{p}=0.002$ \\
$\mathrm{GC}$ EQUIA & 0.092 & 0.159 & 0.224 & 0.424 \\
$\quad$ Ketac molar & 0.205 & 0.205 & 0.715 & $\mathrm{p}=0.274$ \\
$\begin{array}{l}\Delta \mathrm{b}^{*} \\
\text { lonofil Plus AC }\end{array}$ & 0.0025 & & & \\
GC EQUIA & 0.003 & 0.016 & 0.0083 & \\
Ketac molar & 0.0018 & 0.021 & 0.357 & \\
\hline
\end{tabular}

Table 5: Total color difference $\Delta \mathrm{E}^{*}{ }_{\mathrm{ab}}$ and chroma $\Delta \mathrm{b}^{*}$ for tested $\mathrm{Gl}$ restorative materials immersed in distilled water for different aging periods

\begin{tabular}{lllll}
\hline Materials & $\begin{array}{l}\text { Total color difference } \\
\text { at 1 day }\end{array}$ & $\begin{array}{l}\text { Total color difference } \\
\text { at 1 week }\end{array}$ & $\begin{array}{l}\text { Total color difference } \\
\text { at 1 month }\end{array}$ & $\begin{array}{l}\text { Significant } \\
\text { level }\end{array}$ \\
\hline $\begin{array}{l}\Delta \mathrm{E}^{*} \text { ab } \\
\text { lonofil Plus AC }\end{array}$ & 0.128 & & & $\mathrm{p}=0.000$ \\
GC EQUIA & 0.133 & 0.145 & 0.178 & 0.238 \\
Ketac molar & 0.138 & 0.121 & 0.286 & $\mathrm{p}=0.090$ \\
$\Delta \mathrm{b}^{*}$ & & 0.125 & & \\
lonofil plus AC & 0.0078 & & 0.0075 & \\
GC EQUIA & 0.0035 & 0.0073 & 0.0378 & \\
Ketac molar & 0.0003 & 0.002 & 0.0005 & \\
\hline
\end{tabular}

Power Horse energy beverages showed significant discoloration of all materials, increasing with increased immersion time $(p=0.002)$. For group IV, distilled water, all materials' discoloration increased with time elapsed, except for GC EQUIA and Ketac molar, which showed significantly decreased discoloration at 1 week $(\mathrm{p}=0.000)$.

The highest $\Delta \mathrm{E}^{*}$ ab was that of the GC EQUIA in the Red Bull energy beverages group $\left(\Delta \mathrm{E}_{\mathrm{ab}}^{*}, 0.984\right)$ at 1 week period, and the lowest was GC EQUIA in the Code Red energy beverages group $\left(\Delta \mathrm{E}_{\mathrm{ab},}^{*}, 0.072\right)$ at the 1 week period. The highest and the lowest $\Delta \mathrm{E}_{\mathrm{ab}}^{*}$ were for the GC EQUIA material in group II Red Bull and group I Code Red respectively. All tested materials revealed an increase in the total color difference $\Delta \mathrm{E}^{*}{ }_{\mathrm{ab}}$ with time elapsed, however, this was clinically acceptable $\left(\Delta \mathrm{E}_{\mathrm{ab}}^{*},<3.3\right)$ after 1 month of aging (immersion).

With respect to $\Delta \mathrm{b}^{*}$ (change along yellow-blue axis) values where positive $\Delta b^{*}$ indicates a shifts toward yellow color axis, whereas negative $\Delta b^{*}$ denoting a shift toward blue axis color (Tables 2 to 5) represents the mean color measurement.

The color change values of $\Delta \mathrm{b}^{*}$ in all tested groups for 1 day, 1 week, and 1 month were unperceivable by the human eye as $\Delta \mathrm{b}^{*}<1.5$ (clinically acceptable). All materials showed discoloration, increasing color shifting with increased immersion periods.
No significant change was noted for all the materials in all groups after aging at all periods 1 day, 1 week, and 1 month $(\mathrm{p}<0.05)$.

After 1 day of immersion, all tested materials showed positive $\Delta b^{*}$ discoloration toward yellow axis, $\Delta b^{*}$. After 1 day of immersion, Ionofil Plus AC and Ketac molar that was stored in Red Bull showed the highest discoloration ( $p=0.211$, nonsignificant) (Table 3 ).

After 7 days of immersion in energy drinks, all materials showed an increase shift toward yellow axis $\left(\Delta \mathrm{b}^{*}\right.$, positive), the GC EQUIA materials aged in Red Bull energy beverages group II being the heist material discolored (0.971) unperceivable by the human eye, i.e., $\Delta \mathrm{E}^{*}{ }_{\mathrm{ab}}<1.5$ for all tested materials (clinically acceptable).

After 30 days of immersion, a maximum change in $\Delta b^{*}$ for all materials was seen in Ketac molar material $(0.357)$ that immersed in Power Horse solution $(p=0.274$ nonsignificant). All materials immersed in Red Bull and power Horse solutions after 1,7 , and 30 days $\Delta b^{*}$ showed an increased toward yellow axis ( $\Delta b^{*}$, positive) as presented in Tables 3 and 4.

All tested GI restorative materials immersed in the aging solutions revealed color changes of $\Delta \mathrm{b}^{*}$ toward yellow axis is not significant differences. Code Red group ( $p=0.134)$, Red Bull group ( $=0.211)$, Power Horse group $(p=0.274)$, and distilled water group $(\mathrm{p}=0.090)$. 


\section{DISCUSSION}

Color stability of the GI restorative materials has a key role in achieving the aesthetics. ${ }^{21}$ It plays important roles of the requirement for their clinical performance for period of time. ${ }^{22}$ However, a major drawback of GIs is the tendency of discoloration in the oral cavity leading to the replacement of restorations. ${ }^{23}$ Therefore, restorative materials should match well the initial shade and preserve the color change semblance over time in the restored tooth. This study shows the color stability of the three energy beverages which are designed to provide a short-term energy boost, they derive their boost energy from sugar and caffeine. ${ }^{24}$ The three tested GI materials revealed remarkable color changes after 1 day, 1 week, and 1 month of immersion in the three different energy drinks.

A long period of immersion time was used into the study the extensive effects of acidic drinks on the GI restorative materials. ${ }^{8}$ A number of studies have reported the changes in the physical properties of GI materials. ${ }^{22,25}$ The previous studies finding have been demonstrated that the glass filler particles tend to fall out from the materials and the composition component decomposes when exposed to low $\mathrm{pH}$ environments (acidic). ${ }^{26}$ Most of the energy drinks are acidic in nature. Therefore, consumption of acidic drinks for a prolonged period of time may erode the dental tissues as well as GI. The measured color differences were not perceivable to the human eye.

Rough surface retains more stains compare to smooth surfaces ${ }^{26,27}$ preventive agents color. The visual evaluation of the discoloration can be considered acceptable up to the value $\Delta \mathrm{E}_{\mathrm{ab}}^{*}=3.3$, as an upper limit of acceptability. ${ }^{26}$ Color variations $\left(\Delta \mathrm{E}_{\mathrm{ab}}^{*}\right)$ were calculated between the three color positions at 1 day, 1 week, and 1 month of immersion; in 3-D L*a* $b^{*}$ color space was evaluated. The mean values of color change for all tested materials after exposure to all energy beverages, and distilled water control, at 1 day, 1 week and 1 month of immersion are summarized in Tables 2 to 5. Discoloration of all materials exhibited in all immersion groups was significantly different at the three time periods for all groups $(p<0.05)$. Based on the previous studies, total color difference values of 3.3 or greater were considered clinically perceptible whereas $\Delta \mathrm{E}^{*}$ values of $<1$ were regarded as not noticeable by human eye because the human eye cannot detect $\Delta \mathrm{E}^{*} \mathrm{ab}$ values of $<1.5$. The values which obtained were calculated using the colorimeter. ${ }^{28,29}$

Color stability values of GI restorative materials are not different from those of distilled water (the energy beverages contains water in its composition). The total color differences of GI materials, tested in this study, were imperceptible and clinically acceptable when immersed in different energy beverages and the control group of distilled water for 1 day, 1 week, and 1 month. ${ }^{28}$ Total changes in color were considered clinically satisfactory when the GI materials were immersed in distilled deionized water (control group) for 1 day, 1 week, and 1 month, on which confirms that water sorption does not alter the GI color. ${ }^{28}$

Because of the acidity and erosive potential of energy drinks, ${ }^{30,31}$ the GI specimen was immersed in the energy beverages for specified periods of 1 day, 1 week, and 1 month to evaluate the color change by visually as well as using specific instruments. The same procedure and measurements were carried out on each type of material at the three immersion (aging beverages), using the same equipment. This study followed the protocol described previously for dental applications and used calorimeter (Menolta) and the CIE L*a*b* coordinate system ${ }^{31}$. The CIE L*a*b* coordinate system is used to detect minute color variation $\left(\Delta \mathrm{E}_{\mathrm{ab}}^{*}\right)$ with sensitivity, repeatability, and objectivity. $^{26}$

The discoloration in different test groups was significantly different in GI immersed with Code Red ( $p=0.015)$ and Red Bull $(p=0.005)$, Power Horse $(p=0.002)$, and distilled water $(p=0.000)$.

The color change of the tested materials that immersed in Code Red in a period of 1 day, 1 week, and 1 month was not perceivable by the human eye $\left(\Delta \mathrm{E}_{\mathrm{ab}}^{*}<1.5\right)$, where in this group, the discoloration was the lowest value for GC EQUIA (0.072) and Ionofil Plus AC (0.080) (clinically acceptable), and statistically significant values $(\mathrm{p}=0.015)$ Table 2.

When the color changed in the group Red Bull for the tested materials that immersed for a period of 1 day, 1 week, and 1 month was not perceivable by the human eye $\left(\Delta \mathrm{E}_{\mathrm{ab}}^{*}<1.5\right)$, where the highest was GC EQUIA $\Delta \mathrm{E}_{\mathrm{ab}}^{*}$ 0.984 (clinically acceptable), and statistically significant values $(\mathrm{p}=0.005)$ Table 3 .

The total color difference $\Delta \mathrm{E}^{*}{ }_{\mathrm{ab}}$ in specimens immersed in power horse beverages was also increasing by time and statistically significant ( $p=0.002$ ). The discoloration was clinically acceptable and not perceivable by the human eye in the all periods of immersion, where $\Delta \mathrm{E}^{*}{ }_{\mathrm{ab}}$ is $<3.3$ (Table 4 ).

The previous studies reported that the least differences in CIELAB color parameters $\left(\Delta \mathrm{L}^{*}, \Delta \mathrm{a}^{*}\right.$, and $\left.\Delta \mathrm{b}^{*}\right)$ of $1 \mathrm{CIE}$ unit were likely to be observed depending on the CIE L* value, background color, and lighting, while differences in the range 1-2 CIE units have been noticed by the majority of observers. ${ }^{32}$ The color change values of $\Delta \mathrm{b}^{*}$ in all tested groups for 1 day, 1 week, and 1 month were unperceivable by the human eye, as $\Delta b^{*}$ is $<1.5$ (clinically acceptable). All materials behave discoloration, it is increasing color shifting with increased immersion periods. $\Delta b^{*}$ values in tested GI aged with Code Red 
group I were the materials in this aging group shows least effectiveness with this type of energy beverages at the periods of 1 day, 1 week, and 1 month. It was not perceivable by naked eye as $\Delta b^{*}$ is $<1.5$ (clinically acceptable).

The color changes values of $\Delta \mathrm{b}^{*}$ in the GI materials immersed in Red Bull for 1 day, 1 week, and month were not perceivable by the human eye in the all periods $\Delta \mathrm{b}^{*}$ $<1.5$, where all the materials showed the increase of their discoloration toward yellowness (positive values) axis with the increase of aging time. The highest value was GC EQUIA $\Delta \mathrm{b}^{*} 0.971$ (clinically acceptable). It shows statistically not significant values $(p=0.211)$. The Red Bull showed the greatest color shifts toward the yellowness axis. While $\Delta b^{*}$ for the GI materials immersed in Power Horse energy beverages in a period of 1 day, 1 week, and month, the discoloration was lower than other groups and minimal and increasing toward the yellowness, clinically acceptable, and statistically not significant $(p=0.274)$.

This study is in agreement with the previous findings. ${ }^{2,31,33,34} \Delta \mathrm{E}_{\mathrm{ab}}^{*}$ values $(\geq 3.3)$ were considered perceptible as previously reported. In this study, the tested drinks induced a variable discoloration in the GI following 1, 7, 30 , and 60 days clinically acceptable. The discoloration of tested materials was of minimal effect with energy beverages (acidic), whereas, according to previous studies, the effect on the surface texture is high, which leads to the extrinsic discoloration due to accumulation of extrinsic pigments. Although GI restorative materials are bioactive and have fluoride release properties, ${ }^{35,36}$ aesthetic properties are questionable. To improve the properties a number of modifications have been made to the restorative materials. 37,38

\section{CONCLUSION}

The energy beverages affected the color stability of tested GI restorative materials with the increase of aging time. The effect on the color stability of GI was influenced by factors, such as type of solution and the presence of the acids causing erosion. The discoloration was minimal with the energy beverages to GI, but its severances effects on the surface texture which led to the extrinsic discoloration due to accumulation of extrinsic pigments. Further studies with longer period of aging are required for the further study.

\section{REFERENCES}

1. McLean JW. The clinical use of glass ionomer cementsfuture and current development. Clin Mater 2004;7(4): 283-288.

2. Hamouda IM, Ibrahim DA, Alwakeel EE. Influence of energy beverages on the properties of dental restorative glass ionomers. Int J Dent Oral Health 2016, 2(2):1-8
3. McKenzie MA, Linden RW, Nicholson JW. The physical properties of conventional and resin-modified glass-ionomer dental cements stored in saliva, proprietary acidic beverages, saline and water. Biomaterials 2003;24(22):4063-4069.

4. Al-Samadani KH. Effect of energy drinks on the surface texture of nanoflled composite resin. J Contemp Dent Pract 2013;14(5):830-835.

5. Higgins JP, Tuttle TD, Higgins CL. Energy beverages: Content and safety. Mayo Clin Proc 2010;85(11):1033-1041.

6. Ren TF, Feng L, Serban D, Malmstrom HS. Effects of common beverage colorants on color stability of dental composite resins: The utility of a thermocycling stain challenge model in vitro. J Dent 2012;40(Suppl 1):e48-e56.

7. Al-Dharrab A. Effect of energy drinks on the color stability of nanofilled composite resin. J Contemp Dent Pract 2013;14(4): 704-711.

8. Bagheri R, Burrow MF, Tyas M. Influence of food-simulating solutions and surface finish on susceptibility to staining of aesthetic restorative materials. J Dent 2005;33(5):389-398.

9. Barutcigil Ç, Yildiz M. Intrinsic and extrinsic discoloration of dimethacrylate and silorane based composites. J Dent 2012;40(Suppl 1):e57-e63.

10. Park JK, Kim TH, Ko CC, García-Godoy F, Kim HI, Kwon $\mathrm{YH}$. Effect of staining solutions on discoloration of resin nanocomposites. Am J Dent 2010;23(1):39-42.

11. Peutzfeldt A, García-Godoy F, Asmussen E. Surface hardness and wear of glass ionomers and compomers. Am J Dent 1997;10(1):15-17.

12. Ahmed N, Zafar MS. Effects of wear on hardness and stiffness of restorative dental materials. Life Sci J 2014;11(10):11-18.

13. Imirzalioglu P, Karacaer O, Yilmaz B, Ozmen I. Color stability of denture acrylic resins and a soft lining material against tea, coffee, and nicotine. J Prosthodont 2010;19(2):118-124.

14. O'Brien WJ. Dental Materials and Their Selection. $3^{\text {rd }}$ ed. Chicago: Quintessence; 2002. p. 24-36, 210-238.

15. Johnston WM, Kao EC. Assessment of appearance match by visual observation and clinical colorimetry. J Dent Res 1989;68(5):819-822.

16. Ergucu Z, Turkum IS, Aladag A. Color stability of nanocomposite polished with one step system. Oper Dent 2008;33(4): 413-420.

17. Liberman R, Combe EC, Piddock V, Pawson C, Watts DC. Development and assessment of an objective method of colour change measurement for acrylic denture base resins. J Oral Rehabil 1995;22(6):445-449.

18. Satou N, Khan AM, Matsumae I, Satou J, Shintani H. In vitro color change of composite-based resins. Dent Mater 1989;5(6):384-387.

19. Karda B, Jindal R, Mahajan S, Sandhu S, Sharma S, Kaur R. To analyse the erosive potential of commercially available drinks on dental enamel and various tooth coloured restorative materials - An in-vitro study. J Clin Diagn Res 2016;10(5): ZC117-ZC121.

20. Kitchens M, Owens BM. Effect of carbonated beverages, coffee, sports and high-energy drinks and bottled water on the in vitro erosion characteristics of dental enamel. J Clin Pediatr Dent 2007;31(3):153-159.

21. Schulze KA, Marshall SJ, Gansky SA, Marshall GW. Color stability and hardness in dental composites after accelerated aging. Dent Mater 2003;19(7):612-619.

22. Tahmassebi JF, Duggal MS, Malik-Kotru G, Curzon ME. Soft drinks and dental health: A review of the current literature. J Dent 2006;34(1):2-11. 
23. Kennes C, Veiga MC, Dubourguier HC, Touzel JP, Albagnac G, Naveau H, Nyns EJ. Trophic relationships between Saccharomyces cerevisiae and Lactobacillus plantarum and their metabolism of glucose and citrate. Appl Environ Microbiol 1991;57(4): 1046-1051.

24. Abu-Bakr N, Han L, Okamoto A, Iwaku M. Changes in the mechanical properties and surface texture of compomer immersed in various media. J Prosthet Dent 2000;84(4):444-452.

25. Cochrane NJ, Yuan Y, Walker GD, Shen P, Chang CH, Reynolds C, Reynolds EC. Erosive potential of sports beverages. Aust Dent J 2012;57(3):359-364.

26. Celik C, Yuzugullu B, Erkut S, Yamanel K. Effects of mouth rinses on color stability of resin composites. Eur J Dent 2008;2(4):247-253.

27. Shintani H, Satou J, Satou N, Hayashihara H, Inoue T. Effects of various finishing methods on staining and accumulation of Streptococcus mutans HS-6 on composite resins. Dent Mater 1985;1(6):225-227.

28. Al-Samadani KH. Color stability of restorative materials in response to Arabic coffee, Turkish coffee and Nescafe. J Contemp Dent Pract 2013;14(4):681-690.

29. Brook AH, Smith RN, Lath DJ. The clinical measurement of tooth colour and stain. Int Dent J 2007;57(5):324-330.

30. Al-Samadani KH. Surface hardness of dental composite resin restorations in response to preventive agents. J Contemp Dent Pract 2016;17(12):978-984.
31. El Embaby AE. The effects of mouth rinses on the color stability of resin-based restorative materials. J Esthet Restor Dent 2014;26(4):264-271.

32. Zamarripa E, Ancona AL, D'Accorso NB, Macchi RL, Abate PF. Effect of energy density on color stability in dental resin composites under accelerated aging. Acta Odontol Latinoam 2008;21(1):11-15.

33. Mjör IA, Moorhead JE, Dahl JE. Reasons for replacement of restorations in permanent teeth in general dental practice. Int Dent J 2000;50(6):361-366.

34. Syed J, Dharrab AA, Zafa MS, Khand E, Aversa R, Petrescu RV, Apicella A, Petrescu FIT. Influence of curing light type and staining medium on the discoloring stability of dental restorative composite. Am J Biochem Biotechnol 2017;13(1):42-50.

35. Zafar MS. Effects of surface pre-reacted glass particles on fluoride release of dental restorative materials. World Appl Sci J 2013;28(4):457-462.

36. Zafar MS, Ahmed N. Therapeutic roles of fluoride released from restorative dental materials. Fluoride 2015;48(3):184-194.

37. Najeeb S, Khurshid Z, Zafar MS, Khan AS, Zohaib S, Martí JM, Sauro S, Matinlinna JP, Rehman IU.. Modifications in glass ionomer cements: Nano-sized fillers and bioactive nanoceramics. Int J Mol Sci 2016;17(7). pii:E1134.

38. Khurshid Z, Zafar M, Qasim S, Shahab S, Naseem M, Abu RA. Advances in nanotechnology for restorative dentistry. Materials 2015;8(2):717-731. 